\begin{tabular}{|l|l|l||}
\hline \multicolumn{2}{|c|}{ PublisherInfo } \\
\hline \hline PublisherName & $:$ & BioMed Central \\
\hline \hline PublisherLocation & $:$ & London \\
\hline \hline PublisherImprintName & $:$ & BioMed Central \\
\hline \hline
\end{tabular}

\title{
Preventing candidain high-risk patients
}

\begin{tabular}{|l|l|l||}
\hline \multicolumn{2}{|c||}{ ArticleInfo } \\
\hline \hline ArticleID & $:$ & 4095 \\
\hline \hline ArticleDOI & $:$ & $10.1186 /$ ccf-1999-1482 \\
\hline \hline ArticleCitationID & $:$ & 1482 \\
\hline \hline ArticleSequenceNumber & $:$ & 32 \\
\hline \hline ArticleCategory & $:$ & Paper Report \\
\hline \hline ArticleFirstPage & $:$ & 1 \\
\hline \hline ArticleLastPage & $:$ & 4 \\
\hline \hline & & RegistrationDate : 1999-8-26 \\
ArticleHistory & $:$ & OnlineDate \\
\hline \hline ArticleCopyright & $:$ & Current Science Ltd1999-8-26 \\
\hline \hline ArticleGrants & $:$ & \\
\hline \hline ArticleContext & $:$ & 130541111 \\
\hline \hline
\end{tabular}




\section{Keywords}

Candida, candidiasis, colonization, critical care, fluconazole, infection, prophylaxis, peritonitis, surgery

\section{Comments}

This study convincingly shows that fluconazole can be of significant benefit in patients at high-risk of invasive candidiasis. In this population, fluconazole treatment resulted in a statistically significant reduction in mortality and morbidity from Candida infection. The results from this study obviously require further confirmation, as the sample size was small. However, the evidence is strong, as this study was a randomized, controlled, double-blind trial. It will also be interesting to see whether the use of fluconazole prophylaxis will reduce mortality from Candida infections in other patient populations in the ICU.

\section{Introduction}

Fungal infections have become increasingly common causes of nosocomial infections. Candida species account for $78 \%$ of all fungal infections prolonging hospital stay, and are associated with high mortality (estimated at between $27 \%$ and $77 \%$ ). Patients who have had abdominal surgery are particularly at risk from candidial infections. Risk factors for intra-abdominal candidial infections have been identified to include recurrent gastrointestinal perforations, anastomotic leakages, surgery for acute pancreatitis and splenectomy.

\section{Aims}

This study aimed to evaluate the efficacy and safety of intravenous fluconazole for the prevention of intra-abdominal Candida infections in high-risk surgical patients.

\section{Methods}


This randomized, prospective, double-blind, placebo-controlled trial was conducted over 30 months at two university-affiliated hospitals. Patients selected were at high-risk for abdominal candidiasis (recent abdominal surgery with recurrent gastrointestinal perforations or anastomotic leakages). Excluded from the study were patients who had a documented or suspected fungal infection, abnormal liver function, renal failure or high probability of death within $72 \mathrm{~h}$ of entry to the study.

Patients were randomized to receive fluconazole ( $400 \mathrm{mg}$ once a day) or a placebo (5\% dextrose) administered intravenously over $30 \mathrm{~min}$. The drugs were continued until complete resolution of abdominal disease.

Patients were examined daily until one week after discontinuation of drug treatment. Laboratory blood tests and APACHE II scores were taken on entry to the study and repeated at least twice a week thereafter. In addition, cultures of blood, urine, intra-abdominal specimens, respiratory tract, skin and soft tissue were taken three times a week until the end of the study.

The primary end-points of the study were the frequency of, and the time to, intra-abdominal Candida infection in each group. The secondary end-points were the frequency of candidiasis and the emergence or persistence of Candida colonization.

\section{Results}

The 43 patients enrolled in the study were matched in terms of demographic and APACHE II data. Twenty three patients received fluconazole and 20 received placebo. At entry into the study all patients were receiving broad-spectrum antibiotics. Five of the 43 patients developed renal impairment and two, who were receiving fluconazole, had the dose reduced in accordance with the manufacturer's recommendations.

With regard to the primary end-points, only one patient $(4 \%)$ receiving fluconazole developed intraabdominal Candida infection compared to seven patients (35\%) in the placebo group. The patient in the fluconazole group who developed Candida peritonitis had a mixed infection with fluconazolesusceptible C. albicans and fluconazole-resistant $C$. krusei. This was resolved by treatment with amphotericin B. One patient in the placebo group developed pure Candida peritonitis and died, despite treatment with amphotericin B and 5-fluorocytosine.

With regard to the secondary end-points, 26 patients were not colonised with Candida at time of entry into the study. Two patients (15\%) in the fluconazole group and eight (62\%) in the placebo group had Candida isolated from surveillance culture. A total of 25 of the 29 strains (87\%) of Candida isolated were $C$. albicans, all of which were sensitive to fluconazole.

In all, $35 \%$ of patients in each group required abdominal surgery after entry to the study. Seven patients $(30 \%)$ in the fluconazole group and 10 patients $(50 \%)$ in the placebo group died. Of these, four of the placebo deaths were deaths due to the complications of Candida peritonitis. The median length of hospital stay was 21.5 days in the fluconazole group and 33 days in the placebo group. 


\section{Discussion}

Intravenous fluconazole prevented colonisation with Candida, and reduced the rate of invasive Candida in a population of surgical patients who were at high risk of infection. The fluconazole prophylaxis virtually eliminated the morbidity in this group.

A concern, as always, is the development of resistance to anti-microbial agents. $C$. albicans has developed resistance to fluconazole in patients with acquired immunodeficiency syndrome and in those who have received repeated fluconazole doses. In this study, no resistance was found in the Candida isolates. The authors felt that short courses of fluconazole in a small high-risk surgical population was unlikely to encourage the development of resistance to fluconazole.

The authors conclude that administration of anti-fungal prophylaxis to a selected population at highrisk of developing invasive candidiasis, may contribute to a reduction in the morbidity and mortality associated with these severe nosocomial infections.

\section{References}

1. Eggimann P, Francioli P, Bille J, Schneider R, Wu MM, Chapuis G, Chiolero R, Pannatier A, Schilling J, Geroulanos S, Glauser MP, Calandra T: Fluconazole prophylaxis prevents intra-abdominal candidiasis in high-risk surgical patients. Crit Care Med. 1999, 27: 1066-1072 